well for some hours, when tetanus set in, and on the third day afterwards, and if my memory surves me, I believe the sixth from the accident, the poor woman died.

I thought, at the time, if we had given Nature more time-if we had gone secundum naturam, instead of secundum artem, and adopted the principle I once heard a cautious Scotchman impress upon an impetuous Irishman, who told him to "bide a wee," in such difficulties, that a different result would have been recorded.

CASE 2,-H. M'G__, aged 48, a stalwart navvie, while seeking work in Glasgow, during the severe winter of 1848 , received a peremptory summons to visit his wife in Carlisle, if he had any desire to see her alive, as she was very ill. The poor fellow, in the ardour of his affection for his better half, started immediately to walk to Carlisle, a distance of nearly one hundred miles. Labour had been so slack that he had not in his possession as nuch as would pay his fare per rail. He walked the distance in two days, and when nearly at the end of his journey he sat down by the road side and fell asleep. The ground was covered with snow, and it was freezing. When he awoke his feet were stiff and numb, and he felt ill. He managed to get home, and very soon afterwards was seized with typhus. He was conveyed to the Union Fever Hospital, and there received proper medical attendance. He fell under my care after he had been in the fever ward about a month. I found mortification of both feet, involving the whole of one foot as far as the ankle-joint, and leaving a great part of the skin of the heel of the other. A decided line of demarcation had not yet formed, and the fever was still intense, with great prostration of the bodily powers. Stimulants and a nutritious diet being indicated, were persevered in, and from time to time the most seriously offensive parts were removed. No attempt to form an artistic stump was attempted for some months, and when Nature had seemed to have done wer worst, and there was an inclination on her part to reverse her proceedings, her good works were assisted, and flaps formed, and the ends of the tibia and fibula (a slice) sawn off, as the articulating surfaces of these bones were diseased. In a short time a respectable covering united over the ends of the bones, and the man has since moved about freely, walking on the ends of the tibia and fibula, in a better state than he could have done had amputation been performed higher up, and wooden legs substituted for the natural ones. The late Sir C. Bell used to recommend amputation high up in cases of disease of the ankle-joint, as he said, "When artificial legs are used, the length of limb left sticking out behind, in the low-down operation, looked like a rudder to steer the individual on his course by." "What a different tale can now be told by lecturers on surgery! and we have to thank Mr. Syme for the introduction of this improvement in the surgery of the United Kingdom. The final operation on both limbs were here not had recourse to at the same time; one was allowed to heal perfectly before the second was undertaken. In one, the skin of the heel formed an admirable corering; and the advantage of this is apparent up to the present day, for he can bear much more hardship on this limb than on the other, the heel skin of which sloughed from the mortification, and caused some difficulty in forming a proper covering, at the same time allowing one limb to remain as long as its fellow. I feel satisfied in my own mind that if amputation had been performed much earlier, and above the line of demarcation, soon after it had formed, that this poor man would not have recovered, and I should not have had the pleasure of relating this case as favourable to Mr. Guthrie's plans and intimations on the subject of amputation after mortification.

Carlisle, June, 1850

\section{CONVULSIONS FOLLOWED BY MANIA, AND ACCOMPANIED WITH ENTIRE LOSS OF SPEECH DURING PREGNANCY.}

Br SIDNEY HENSON, Esq., Edinburgh.

I WAs summoned to a young married woman, to whom, on the 29 th of December last, pains had come on at five P.M., which ultimately proved to be spurious, although they so closely resembled labour-pains, that I was quite deceived by them. She had miscarried in her first pregnancy when about three months advanced, and this was her second, which she dated from St. Patrick's day, the 17 th of March. She had last menstruated in the week before, so that she believed she was at her full time. The pains continued with but short intervals, until the night of the 1st of January, when convulsions came on, which lasted about two hours. The next morning she was quite delirious, and remained so until the morning of the 5 th. On the evening of the 6 th, these false pains were very violent, so much so, that she had administered to her, by the advice of Dr. Weir, one of the physicians to the Maternity Hospital, (who had seen her with me once or twice before,) sixty minims of laudanum, which not producing sleep shortly, were followed by twenty minims of solution of acetate of morphia, and a drachm of chloric ether. This soon caused her to fall into a deep sleep, which lasted for eight or nine hours, when she awoke quite conscious. She had not spoken since she had the convulsions. Now, however, she could say "You wee rogue," and with difficulty about half the alphabet. She continued tolerably well until January 16 th, when I was again called to her, about eight P.M. At two P.M., January $17 \mathrm{th}$, she was delivered of a living, but feeble female child, and the very moment the child was born she could speak without any difficulty whatever, and convalesced rapidly.

Remarks.- When first called to her, I ascertained, upon inquiry, that her bowels were open, having been relieved during the afternoon. The pains were seated both in the back and abdomen. At noon, the next day, I gave her a little chloroform to inhale, but fortunately the husband objected, and I did not give her much, or it would have borne the odium of causing all these disasters. In the afternoon, I gave her forty minims of tincture of opium, which procured her a few hours' sleep. This was repeated several times, castor-oil being administered after each dose.

Another circumstance which I think worthy of notice, is as to the duration of the pregnancy. I was first called to her on the 287 th day after she had become pregnant, and she was not delivered until the 17 th of January, the 306 th day. St Patrick's day (she told me) was on a Saturday, and she had last menstruated the previous Saturday, so that she must have been mistaken, I think, although she will not hear of the possibility of such a thing.

University, Edinburgh, 1850.

ON A

\section{CASE OF POISONING WITH HYDROCHLORIC}

$$
\text { ACID.-RECOVERY. }
$$

\section{Bx DAVID PRICE, M.D., F.L.S., Margate.}

THE instances of the employment of hydrochloric acid for suicidal purposes are extremely rare. Orfila, in his great work on Poisons, mentions but one case. Christison remarks, "It s not a little singular that there should be on record, as far as I know, but one case of poisoning with a substance so energetic and in such common use;" and Dr. Alfred Taylor, in his recent work on Medical Jurisprudence, observes, "In the coroners' report for England during the years 1837 and 1838 , out of 527 cases of poisoning, there was not one where this acid was the poison used. I have been able to collect the reports of only three cases of poisoning by muriatic acid that have occurred in the metropolis during a period of thirteen years. From this statement it will be seen that the medico-legal history of this kind of poisoning must be very incomplete.

The case I wish to record is the following:-On March 31st, a person aged 30 , whilst under the influence of liquor, $s$ allowed rather more than an ounce of strong hydrochloric acid. He states that he took it, as he usually takes medicine, by holding his head back, and throwing the contents of the glass into his throat : this fact was evidenced by the tongue being denuded of its natural covering only towards the base. The occurrence took place about one o'clock in the day. I arrived in less than twenty minutes afterwards with the stomach-pump; but I could not get his mouth open for the purpose of gagging, until I had closed his nostrils, and compelled him to breathe through the mouth. I was then able, with assistance, to force his jaws open by means of an iron chisel, and to introduce gently the small tube of the stomach-pump. About a pint and a half of tepid water was forced into the stomach, and when withdrawn, was tinged with blood, and had in it some coagula. This first water was carefully preserved. About the same quantity of water, with carbonate of soda in it, was immediately injected, and when withdrawn, effervesced powerfully in the basin. Subsequently, a similar quantity was used again and again, until litmus paper ceased to indicate the presence of acid, and turmeric paper testified that the fluid was alkaline. A few ounces of plain water were then thrown into the stomach, and the utmost quietude was enjoined. There was no particular constitutional disturbance during the after part of the day, and he passed a tolerably quiet night. Water, with gum arabic and isinglass dissolved in it, was given to him sparingly. 
April 1st.-The same fluid was continued, and a purgative enema administered, which acted well; pulse moderate; great aversion to everything.

2nd.-He appeared much the same; pulse ranging from 80 to 100; ptyalism from the first has been distressingly constant; he complains of much pain in the course of the cesophagus, and in the cardiac extremity of the stomach.

$3 \mathrm{rd}$ - - Had most severe pain during the night, apparently from swallowing a little dissolved calf's-foot jelly, and hiccup came on in the afternoon; this distressed him much, and he was very feeble; a disagreeable odour was perceptible in the eructations.

4th. - Had a good night, until five o'clock, when the pain became very severe; the odour from the stomach was highly offensive to himself and the attendants. As the pain was now becoming intolerable, small doses of muriate of morphine were given from time to time, and the bowels were kept in action by repeated enemas.

5th.-I was called up to him in the night, in consequence of arterial hæmorrhage from either the csophagus or stomach; the coagula which formed in the stomach caused him to vomit; pain very great, and the hiccup more frequent and distressing. A dose of morphine tranquillized him during the day, and he appeared better, but hæmorrhage recurred in the afternoon.

6th.-Every way better, but troubled with a constant discharge of glairy fluid from the throat. Allowed to take some arrow-root.

7th.-Less fotor and hiccup; evacuations from the bowels very black, and highly offensive. He feels better, and in less pain.

8th.-Motions still very black and fotid, but he feels in every way better.

From this time onward he complained of much pain in the stomach, and sinapisms were occasionally applied. The discharge of glairy fluid continued for some time in large quantities. The fluid first drawn from the stomach was analyzed by my son, Dr. D. S. Price and Mr. Nicholson, at the Royal College of Chemistry, and I subjoin their report:-

"A careful quantitative examination of the liquid sent us has proved the poison in question to be hydrochloric acid. Metals were particularly songht for, but with negative results. On the bottle being uncolked, a strong spirituous odour was perceptible. In order to verify the presence of alcohol, the highly acid fluid was neutralized with pure carbonate of soda, and subjected to distillation in a water-bath. The distillate was tested for alcohol, by adding to it a few drops of concentrated solution of bichromate of potassa and hydrochloric acid; instant reduction of the chromic acid ensued on heating, the odour of aldehyde being at the same time powerfully developed. The contents of the retort were remored into a dish, evaporated to dryness, and ignited, in order to destroy organic matter, the residue was treated with water, filtered, and the hydrochloric acid determined in the usual manner with nitrate of silver. The anoun of chloride of silver obtained corresponds very nearly to about three drachms and a half of muriatic acid, sp. gr. $1 \cdot 17$, the common fuming commercial acid.

$$
\text { (Signed) David S. Price, Ph. D. }
$$

E. Chambers Nicholson."

The success with which the stomach-pump was used in this case, proves, contrary to some opinions, that it may and ought to be used at an early stage in cases of poisoning with mineral acids.

Margate, July, 1850 .

ON A

GUNSHOT WOUND OF THE FEMORAL ARTERY, PRODUCING A FALSE ANEURISM. OPERATION, AND RECOVERY.

By HENRY WATERWORTH, Esq., M.R.C.S. \&c., Newport, Isle of Wight.

ON Wednesday, April 25th, 1849, I was sent for to Mr. D. Waged 21 , who had received a wound in the thigh, from the accidental explosion of an air-gun. The ball had eniered about the middle of the thigh, exactly over the course of the femoral artery; profuse hæmorrhage ensued, but was soon arrested, by the patient himself tying a handkerchief around the limb. Fearing the dangerous proximity of the wound to the artery, I determined to take no steps to explore it until I had procured assistance, which was promptly rendered by $\mathrm{my}$ friend, $\mathrm{Mr}$. Tuttiett. After slightly dilating the wound, and carefully probing it, we found it to extend downwards and inwards, and then upwards, and we hoped the femoral artery had escaped injury. Water dressing and a bandage were applied, and perfect quiet was enjoined. On visiting him the next morning, I found he had passed a good night, and there had been no further hæmorrhage; but on my second visit, in the evening, his friends were in great alarm, recurrence of the hæmorrhage having taken place, though this had been again stopped before I saw him. I now observed a pulsation over the artery, and a vibratory murmur, which was evident throughout the thigh. I remained during the night with him, and the next day had another consultation with $\mathrm{Mr}$. Tuttiett, who agreed with me as to the nature of the case, and the almost inevitable necessity for an operation. This being communicated to his friends, we had the patient carefully removed to Newport, his residence being six miles in the country. In the meantime, we thought it right to try the effect of a compress and bandage from the toes to the groin, for a day or two. He continued in the same state, and on Sunday, the 29 th, a consultation was held with my friend Staff-Surgeon Dowse, of Parkhurst Barracks, by the wish of the patient's friends, as they had heard " he had been in a great many wars." He also coincided with our opinion, and we fixed on the next day for the operation. The question now arose, whether we should cut into the sac at the seat of injury, and tie the vessel above and below, or merely tie the artery in the upper part of the thigh-a much easier operation. After mature deliberation, we decided on the former, being more especially led to this opinion from reading Mr. Guthrie's lectures on this subject in THE IANCET. The operation was rendered rather tedious, from $m y$ bein embarrassed by considerable venous hæmorrhage, from the application of the toumiquet, the use of which was rendered necessary by a violent gush of arterial blood taling place immediately on open. ing the sac, notwithstanding very firm pressure was made on the artery above. The ligatures were placed round the artery without difficulty; the wound by which the ball had entered being very perceptible. The patient was kept under the influence of chloroform until towards the close of the operation. The whereabouts of the ball could not be detected. The $\operatorname{limb}$ was care. fully enveloped in filannel, but no alteration in temperature was perceptible at any time. The last ligature came away on the fourteenth day, and the patient recovered without an unfavourable symptom, excepting a small abscess on the dorsum of the foot, which required opening. He returned home in the beginning of June, and has felt no inconvenience from the ball, the presence of which can be felt in the region of the wound.

Newport, 1850 .

\section{ON COTTON WADDING AS AN APPLICATION TO BED-SORES AND VARICOSE ULCERS.}

Bx ROBERT JONES, M.R.C.S.L., Conway, North Wales.

I WAs summoned to visit a young girl, aged 16, residing some distance in the country, who had been laid up with typhus fever for the previous month. I had seen her for the first time about a fortnight before. It is probable that I might not have been called to this case, had not the nurse observed (to use her expression) that the patient was getting as black as a coal under her. Haring examined the poor girl, I found that matters were almost as bad as the nurse bad stated; the integuments covering the nates were quite black, and the posterior spine and crest of the ilium almost laid bare; the discharge therefrom was very profuse and offensive. She was very weak, and dreadfully emaciated. Her tongue being clear, and bowels open, I desired them at once to give her some wine and bark, at the sanve time allowing her some nourishing broth and beef tea. It occurred to me that $I$ would apply some cotton wadding to the part, with the intenticn of giving her a soft cushion to lie on, as well as to absorb the abundant discharge; she complained and cried much from her back, but after the application was made she appeared much relieved. I made my second visit in three days after, having desired the nurse not to remore the cotton, except in places where it became moist from the discharge. On examination, I found things going on farourably, the part covering spine and crest of ilium were granulat ng very nicely, the slough covering them had already partially separated, and the parts beneath were looking very well. I did not visit her again until to-day (March 4th), and I find that she is convalescent. I have also treated successfully a few cases of varicose ulcers of the lower extremities, by the application of the cotton wadding; the manner of applying it is simply to cover the ulcer, and dressing the patient every second or third day, a roller being applied after the cotton. At the same time I enjoin pexfect quietness, and keeping the limb in the horizontal position. I have found three weeks or a month a sufficient time to get them well. North Wales, 1850. 